\title{
Research Analysis of Built Environment as a System: Implementing Research Through Design Methodology
}

\author{
Hari Kumar Suberi * \\ Trier University of Applied Science Birkenfeld, Institute for Transformation Design HBK Braunschweig, Trier, Germany
}

\section{OPEN ACCESS}

Edited by:

Azni Zain Ahmed,

Universiti Teknologi Mara, Malaysia

Reviewed by:

Ali Sohani,

K.N.Toosi University of

Technology, Iran

Costantino Menna,

University of Naples Federico II, Italy

Taofeeq Ibn-Mohammed,

University of Warwick,

United Kingdom

*Correspondence:

Hari Kumar Suberi

harikumarsubedi@gamil.com

Specialty section:

This article was submitted to Sustainable Design and Construction,

a section of the journal Frontiers in Built Environment

Received: 05 January 2021 Accepted: 29 October 2021 Published: 03 February 2022

Citation:

Suberi HK (2022) Research Analysis of Built Environment as a System: Implementing Research Through Design Methodology. Front. Built Environ. 7:649903. doi: 10.3389/fbuil.2021.649903
Building is a process of technology that enables human wellbeing by engaging a multitude of stakeholders. However, it is often seen in the literature that all stakeholders involved in the building process are disintegrated, which seems to be a management and systemic orientation problem when trying to address the built environment as a sustainable system design. That means the design and design aesthetics of any building cannot be simply influenced by technological revolution and efficiency improvements to attain the three pillars of sustainable development. A systemic transformation of the whole process is a pre-requisite, which is complex and oft underestimated mainly due to the lack of subjective characteristics involved available for transformation research, that addresses policy choice in the development of a paradigm shift. Addressing built environment as a system for transformation research practice, this study extensively reviewed the UNEP built environment report to identify global variables that define the roughly correct system as an artifact to be studied. The UNEP report covers the system level transformation requirement until 2003, which seems to be more or less the same in almost all the research studies as of now. Using the Vester Sensitivity Model, the roughly correct built environment as a system is analyzed to identify the future leverage potential and variables' interdependency. The in-depth systems analysis indicates global variables Enabling condition and New material are potential system leveraging variables for built environment system transition to sustainable design, which require further scrutiny. The leveraging variables are influenced by other global variables which can only be negotiated for sustainable development goal actualization for future success.

Keywords: built environment, leverage point, influence factors, new material, global variables

\section{INTRODUCTION: SUSTAINABLE BUILDING DESIGN}

When limits to the growth model were first projected, the fundamental challenges identified were systemic intervention and enforcement mechanisms to enable de-growth strategy actualization (Meadows et al., 1972a). That suggests reorganizing new methods of synergy between industrial, social, economical, and environmental criteria to fulfill sustainable development goals (Meadows et al., 1972a). Sustainable development is therefore an interdisciplinary and philosophical ideology that is defined as a development model wishing to address that human societies must live and meet their needs without compromising the ability of future generations to meet their own needs 
TABLE 1 | Global influence factors of built environment design as a system.

\begin{tabular}{|c|c|c|c|}
\hline Literature & Key control factors & Building subsystem & Source \\
\hline $\begin{array}{l}\text { Realizing the sector's potential for contributing to } \\
\text { sustainable development }\end{array}$ & Stakeholders role in the building sector & Stakeholder Participation & Bakens (2003) \\
\hline Towards a sustaining architecture for the & Industrial systems are in closed-loop cycles of & Construction material & McDonough and \\
\hline 21stcentury: the promise of cradle-to-cradle design & production, recovery, and remanufacture & characteristics & Braungart (2003) \\
\hline Life-cycle analysis of the built environment & $\begin{array}{l}\text { Often the default data represent the major qualifying } \\
\text { criteria that are highly complex }\end{array}$ & $\begin{array}{l}\text { Built environment ecological } \\
\text { footprint }\end{array}$ & $\begin{array}{l}\text { Kohler and Moffatt } \\
\text { (2003) }\end{array}$ \\
\hline Drivers for sustainable construction & $\begin{array}{l}\text { Low cost and informal housing to address the general } \\
\text { population categories }\end{array}$ & $\begin{array}{l}\text { Justice and fairness concerning } \\
\text { housing infrastructure distribution }\end{array}$ & $\begin{array}{l}\text { Force Sustainable } \\
\text { Develop (2003) }\end{array}$ \\
\hline $\begin{array}{l}\text { The role of policies in promoting sustainable } \\
\text { practices }\end{array}$ & $\begin{array}{l}\text { Policies aimed at specific issues are not enough; a shift to } \\
\text { "dematerialization "is required }\end{array}$ & $\begin{array}{l}\text { Enabling conditions for a } \\
\text { sustainable built environment }\end{array}$ & Rovers (2003) \\
\hline $\begin{array}{l}\text { Do standards and regulations supply the necessary } \\
\text { incentive for sustainable building? }\end{array}$ & $\begin{array}{l}\text { Standardization of economic, environmental, and social } \\
\text { factors for building system }\end{array}$ & $\begin{array}{l}\text { Incentive mechanism for } \\
\text { sustainable building design }\end{array}$ & $\begin{array}{l}\text { Strand and Sverre } \\
\text { (2003) }\end{array}$ \\
\hline Life-cycle costing in the construction sector & $\begin{array}{l}\text { the systematic consideration of all relevant costs and } \\
\text { revenues associated with the acquisition and ownership } \\
\text { of an asset }\end{array}$ & Economic value addition & Clift (2003) \\
\hline $\begin{array}{l}\text { Land use and sustainable buildings: design and } \\
\text { construction in southern Brazil }\end{array}$ & $\begin{array}{l}\text { barriers to incorporating sustainability issues in land use } \\
\text { planning and project design in developing countries }\end{array}$ & $\begin{array}{l}\text { Spatial dynamics of the built } \\
\text { environment }\end{array}$ & Sattler (2003) \\
\hline $\begin{array}{l}\text { Sustainable building services in developing } \\
\text { countries: the challenge to find "best-fit" } \\
\text { technologies }\end{array}$ & $\begin{array}{l}\text { Household utility system management as a key success } \\
\text { condition for sustainable building }\end{array}$ & Availability of basic utility facilities & Bunn (2003) \\
\hline $\begin{array}{l}\text { Concepts and instruments for a sustainable } \\
\text { construction sector }\end{array}$ & $\begin{array}{l}\text { Resource productivity is considered over a building's } \\
\text { entire life cycle (MIPS) and the material flow analysis }\end{array}$ & Building energy efficiency & $\begin{array}{l}\text { Holger and Buerkin } \\
\text { (2003) }\end{array}$ \\
\hline Construction products and life-cycle thinking & $\begin{array}{l}\text { Building material product choice based on life cycle } \\
\text { analysis of the product }\end{array}$ & Alternative building materials & $\begin{array}{l}\text { Edwards and } \\
\text { Bennett (2003) }\end{array}$ \\
\hline $\begin{array}{l}\text { Procurement of sustainable construction services in } \\
\text { the United States: the contractor's role in green } \\
\text { buildings }\end{array}$ & $\begin{array}{l}\text { Identify the value of construction services in the } \\
\text { processes and decision-making that are critical to } \\
\text { sustainable building }\end{array}$ & $\begin{array}{l}\text { Sustainable material procurement } \\
\text { standard }\end{array}$ & Riley et al. (2003) \\
\hline $\begin{array}{l}\text { Social aspects of sustainable construction: an ILO } \\
\text { perspective }\end{array}$ & $\begin{array}{l}\text { Social justice and construction workforce standard } \\
\text { practice }\end{array}$ & $\begin{array}{l}\text { Job availability in the construction } \\
\text { sector }\end{array}$ & Wells (2003) \\
\hline $\begin{array}{l}\text { Promoting innovation in construction SMEs: an EU } \\
\text { case study }\end{array}$ & $\begin{array}{l}\text { SMEs co-operation and one-stop solution for building } \\
\text { services }\end{array}$ & Technology as an enabler & $\begin{array}{l}\text { Wharton and Payne } \\
\text { (2003) }\end{array}$ \\
\hline $\begin{array}{l}\text { Tools for environmental assessment of existing } \\
\text { buildings }\end{array}$ & Building performance management system & $\begin{array}{l}\text { Awareness creation on } \\
\text { sustainable built environment }\end{array}$ & $\begin{array}{l}\text { Boonstra and } \\
\text { Pettersen, (2003) }\end{array}$ \\
\hline $\begin{array}{l}\text { Deconstruction: the start of a sustainable materials } \\
\text { strategy for the built environment }\end{array}$ & Building material recycling and up-gradation & Life span of a building & Kibert (2003) \\
\hline $\begin{array}{l}\text { Integration of EMS into national regulatory } \\
\text { frameworks for offshore oil and gas production }\end{array}$ & $\begin{array}{l}\text { Environment management system for building } \\
\text { construction for green growth }\end{array}$ & Human wellbeing and resiliency & Ifesi (2003) \\
\hline
\end{tabular}

(Brundtland, 1987). The built environment is an unavoidable human need which leaves a strong ecological footprint, and needs to be conserved for the future generation in a coordinated manner rather than focusing on a particular system in isolation (UNEP, 2003). Thus the idea of sustainable building that incorporates conceptual frameworks such as, resource conservation, cost efficiency, and human adaptation, as well as a general knowledge on how the decisions made support providing justifiable built environment policy choices (Akadiri et al., 2012). Similarly, the policy as an enabler curtails the need for building structures to follow sustainable design practice as desired in EU building design policy (Tsimplokoukou et al., 2014). Addressing the policy choice, the nomenclature of sustainable design is transformed from conventional building to green building these days (Behnam, 2017). Researchers have also attempted to assign attributes to building construction and its sustainability principles (Zabihi et al., 2012). These attributes often enable building design to mimic nature, and the "passive building" is gaining popularity for meeting sustainability goals (Iyengar, 2015). On the other hand, building is a process involving interdisciplinary stakeholders such as civil, electrical, and material engineers that enable holistic design in terms of structure weight and material choice, utility system efficiency, and system innovation potential (Wang and Adeli, 2014). However, the choices made regarding the built environment are inevitably influenced by the economy, community, and ecology, which require robust assessment tools and techniques. The research theme of capturing building energy has been extensively analyzed with a special focus on energy efficiency and building performance (Uidhir et al., 2020; Walker et al., 2020). Under this theme at least 50 research articles and 5 reviews have been published in 2020. Similarly, in 2021 the same theme is under progress with the same focus that enables the consideration of purely technical variables for building sectors (Pavlović et al., 2021; Zhao et al., 2021). There are at least three research articles published and others in progress. In this semi-research review article, additional system variables are considered that enable fairness and justice to be visible where human agency is involved as a stakeholder to define the built environment as a complete system inclusive of technical variable choice.

The US Environmental Protection Agency (EPA) suggests that for the built environment site selection to be smart, it will require, 
compact, walkable, and mixed-use development that takes advantage of existing infrastructure and protects critical natural lands (EPA, 2013). Therefore it is critical to identify the global variables to design the built environment as a system. To some extent an integrated version of stakeholder contribution is addressed in the United Nations Environment Programme (UNEP) publication that provides an inclusive system image of the built environment (UNEP, 2003). Based on the UNEP report on the control conditions for sustainable building and construction, the global variable can be picked for the built environment to be observed as a system as summarized in Table 1. This will give a systemic image and the built environment as a system can be viewed as an artifact to be studied for transformation research practice and policy analysis.

The UNEP report as a basis for variable selection is valuable, but at the same time, it is often specialized, each discipline addressing pre-defined specific goals set by different authors. Therefore we can conclude from Table 1 that the global variables are disintegrated from the design and standardization of the sustainable built environment as a system. It appears that the LCA-based decision making is appealing but there is a fundamental problem of default data usage. The LCA study is a software-based research endeavor that limits the use of default data and specified system boundaries for decision support (Oregi et al., 2015; Ramírez-Villegas et al., 2019). On the contrary, holistic decision support is negotiable and contextual and can be evaluated based on matrix-based system inquiries and understanding their feedback effect for the design of a holistic built environment as a system (Vester, 2012; Jonas and German Narrative, 2018). Sustainability goals are highly contextual and interdisciplinary, and apply to the built environment as system design considerations. For that purpose, leveraging the built environment as a system, it is critical that the system's sustainability can be enabled by understanding the influencing effect of global variables, which is missing in the UNEP defined built environment as isolated sub-systems.

\section{Research Scope}

The review work in this study is slightly different from that of the conventional approach of review articles. The main differences are the approach applied and the objective of the review. The review adopted in this research is mostly to establish the potential variables that address the systemic inquiry of any system. The current study is however referring to the built environment as a system among many other systems in order to address sustainable development goals. This linearity has been influencing the scientific domain of many research works and it is always claimed as a new contribution in scientific discourse. However, the linearity justification is heavily influenced by the specificity of the research problem statement, which often leads to precisely the wrong result for application purposes, especially when it comes to the decision-making process based on these research findings. The linear cause and effect identification is a deduction of any particular problem statement, which is already a manipulated simplification of an actual systemic problem. As soon as a system is introduced, the manipulated and data-supported research work can be easily reviewed and negotiated. This is the main objective of this review article, where complexity has been integrated as a key influencing factor at various levels of the system and its subsystem. Therefore, this literature review enables us to identify the global variable set to understand the system and to identify the significance of this variable for further research. Hence, the system as-it-is is presented as a negotiable endeavor rather than making it as a simple cause and effect relationship, which is mostly the case in almost all research practice including that of the latest ideas around sustainable development and green growth as tools for sustainability, as well as being used for greenwashing purposes.

The paper is introduced through key literature that potentially defines built environment as a system supported by global variables, which is adopted from the UNEP report contributed to by many different authors. The report captures to some extent the global variables that are necessary to visualize the built environment as a system. This is discussed in section one as the background of the review. Section two covers the analysis of the variables that are further screened using Vester Sensitivity analysis, which further increases the systemic complexity. The system complexity is methodologically and chronologically presented in sub-headings 2.1-2.6. This section is a major contribution of this study as it clearly introduces negotiable research to the issue of built environment sustainability rather than a specified research problem seeking successful decision support in an actual situation. They can be applied to many areas where complex decisions are not easily addressed through linear research practice. Based on these findings, section three highlights some methodological shortcomings of systemic study. In section four key normative results are presented, and section five briefly elaborates with a specific case study as an example.

\section{MATERIAL AND METHOD}

In this review, the internet database search was carried using the keyword phrase "built environment as a system". There is almost no literature published with this keyword, so the search result mostly showed sustainable built environment studies exclusive of systemic world view. Based on this limitation, the UNEP report which elaborates on sustainable building and construction is extensively reviewed to define the global variables to image the built environment as a system and identify a holistic image of the built environment (UNEP, 2003). Sustainable building and construction covers almost all development from 2003 to present without much change in the vision and goal for the development of the building sector. Therefore a system image can be built from the UNEP report as a baseline study and used to visualize the built environment as a system, and referred to as an artifact to be studied. This way the study significantly addresses a holistic world view for policy recommendation for building sectors exposing the megatrend of rural-urban dynamics. Thus the study differs from many review research practices, which is here referred to as systems analysis. Systems analysis is a complex process and is frequently identified as a troubling problem in management terminology in actual operational conditions (Ben and Peter, 2018; Rittel and Webber, 1973). However, the 
operational practice is heuristically oriented which will require a participatory approach (Ulrich, 1993; Ulrich and Reynolds, 2010). Thus, the formal scientific methodologies defining the research paradigm are insufficient to understand the leverage condition of the system (Vester, 2012; Vester, 2007b). Therefore, defining the problem situation is no more linear for the future sustainability of the system and its design considerations (Jonas and German Narrative, 2018; GausemeierManagement, 1998; Jonas, 2007). This gives rise to a paradigm shift in research practice and therefore the design as an alternative methodology is selected, which holistically addresses the complexity involved in the system design (Jonas and German Narrative, 2018; Jonas, 2007; Gaziulusoy and ErdoğanÖztekin, 2019). Therefore, research through design is applied for the analysis of the built environment as a system to identify the leverage conditions for detailed assessment (Jonas and German Narrative, 2018).

Research through design enables the holistic assessment of global variables defining the system for leverage point identification, which involves Analysis-Synthesis-Projection (Jonas and German Narrative, 2018; Jonas, 2007; Jonas et al., 2008). Analysis-Synthesis-Projection integrates a system under investigation based on ontological and epistemological perspectives addressing the problem situation (Scotland, 2012). For that purpose systems analysis in this study is carried using the Vester approach of cross-impact analysis and feedback control (Vester, 2012; Vester, 2007b). The identified leverage point, which is based on the analysis phase, is further assessed with the help of scenario logic (Rittel and Webber, 1973; GausemeierManagement, 1998). This approach allows system boundary definition and potential integration of the stakeholders involved into the design of a system (Ulrich, 1993; Ulrich and Reynolds, 2010; Ulrich, 2012). The design of a system is a normative endeavor initially for roughly correct system image visualization and is subject to extensive stakeholder participation for defining the system. This is applicable to both technical and non-technical research practice where critical leverage points help to avoid the side effect contained in it for the development of intended good practices (Jonas and German Narrative, 2018; Rittel and Webber, 1973; Vester, 2007b; GausemeierManagement, 1998). On the other hand, the Life Cycle Analysis (LCA) has been prioritized for decision support for the built environment (Kohler and Moffatt, 2003; Oregi et al., 2015; Asif et al., 2007). The application of LCA-based decision support is only meaningful after the system problem is clearly known. The LCA approach is valuable for single products rather than useful for assessing the built environment as a system. Therefore, methodically life cycle analysis is more appropriate for impact evaluation of specific variables, although construction material product default values are mostly used in the impact calculation due to the complexity involved (Asif et al., 2007; Asif et al., 2017).

In this study, the Analysis phase of research through design is applied for critical leverage point identification from the potential global variables listed in Table 1, which is further analyzed in the Vester Sensitivity model to generate a roughly correct system image of the built environment (Vester, 2012;
Vester, 2007b). The potential innovation scope is then projected for building design.

The detail analysis is a methodological framework in an iterative process outlined in Built Environment Systems Analysis Using Vester Sensitivity Model through 2.6. Note that the built environment systems analysis is an iterative negotiation process that requires stakeholder input rather than depending only on technical and empirical evidence for actual scenario projection. Therefore, system design is a process involving stakeholder engagement for user-centric built environment system design. Such approaches are very rare in the mainstream scientific discipline where a predefined research problem statement is addressed for decision-defining criteria. Such decision support will influence the business growth projection where market manipulation can easily influence the research endeavor.

\section{Built Environment Systems Analysis Using Vester Sensitivity Model}

The Vester Sensitivity model is a software-supported system assessment that enables user-defined system negotiation based on the self-regulatory dynamic of the system, and enables usercentric decision support using feedback (Vester, 2012; Gallen, 2006). Systems analysis is used in various studies such as Mobility Systems, Tourism, and Sustainable development scenario projection (Vester, 2012; Vester, 1990). The systems analysis in the Vester Sensitivity model follows a chronological order that involves nine different steps in the iterative process, they are as follows:

1) System description: defining system boundary, nature of influence factor, the meaning of the interdependency, and a rough system image identification.

2) Variable set: defining the system by consideration of the variables with the help of stakeholder support and the observer justification.

3) Criteria matrix: variables relevance test, which is based on the theory of a complex system to define the system.

4) Impact matrix: identification of variables influencing effect in the system to figure out the leverage potentials, which is based on active and passive sum logic.

5) Systemic role: The role played by the variables in the system according to the impact matrix evaluation.

6) Effect system: Variables' cybernetics and identification of feedback effect for uncertainty sorting to enable analytical decision support.

7) Partial scenario: Testing what if conditional logic for system transformation and uncertainty testing.

8) Simulation: The critical variables influencing effect and future projection of the intended development.

9) Cybernetic evaluation: Overall system test using the eight basic rules of bio-cybernetics.

The Vester Sensitivity Analysis is an older software-supported tool, which is often available in a German version for systems and policy analysis that enables real-time systems negotiation, based 
TABLE 2 | Building system variables.

\begin{tabular}{|c|c|c|}
\hline SI. no & $\begin{array}{l}\text { Building system global } \\
\text { influence factor }\end{array}$ & Global variable \\
\hline 1 & Stakeholder Participation for the building design process & Participation \\
\hline 2 & Construction material characteristics & Material characteristics \\
\hline 3 & Built environment ecological footprint & Ecological footprint \\
\hline 4 & Justice and fairness in housing infrastructure distribution & Justice and fairness \\
\hline 5 & Enabling the conditions for a sustainable built environment & Enabling condition \\
\hline 6 & Incentive mechanisms for sustainable building design & Incentive mechanism \\
\hline 7 & Enabling economic value addition with sustainable design & Value addition \\
\hline 8 & Spatial dynamics of the built environment & Spatial dynamics \\
\hline 9 & Availability of basic utility facilities in the building & Utility facilities \\
\hline 10 & Building energy efficiency consideration & Energy efficiency \\
\hline 11 & Alternative building materials availability & New materials \\
\hline 12 & Sustainable material procurement standards & Procurement standard \\
\hline 13 & Job availability in the construction sector & Job availability \\
\hline 14 & Technology as an enabler for sustainable design & Technical support \\
\hline 15 & Awareness creation on the sustainable built environment & Awareness creation \\
\hline 16 & Life span consideration of a building & Life span \\
\hline 17 & Human wellbeing and resiliency considerations & Human wellbeing \\
\hline
\end{tabular}

on system defining variable sets in an iterative process involving a multitude of stakeholders (Jonas and German Narrative, 2018; Model, 2014). The system analysis covers the complex behavior patterns developed by the variables by involving relevant stakeholders to address the bio-cybernetic effect of the system known as biological design (Vester, 2012; Model, 2014). In this study systems analysis using the Vester Sensitivity tool addresses only the system analysis phase where the future scenario projection offers multiple and optional futures that require further research. Therefore, steps one to six only are used for built environment system analysis. Steps seven to nine can be better addressed by life cycle assessment methodologies or scenario technique alternatively for future scenario projection for specific case. The intention of this study is to identify a holistic system so that further research can be carried using the holistic built environment as a complete system. The semantics of the built environment as a system is defined by global variables to identify the leverage point and critical influence factors for further research. Hence the conclusion drawn from this study should be used as a normative hypothesis for stakeholder engagement and to enable empirical testing. Actual stakeholder engagement and empirical tests are beyond the scope of this article.

\section{System Description: Global Variable Identification}

Consideration of the built environment as a system is rare in scientific literature because of the complexity involved. It is often the case that the buildings are integrated into the urban plan, where the building as a system is missing. For example, the experimental process involving research through the design of urban systems is gaining popularity where the urban system is negotiated in a living lab with the involved stakeholders (Geyer et al., 2014). Thus architecture and civil engineering design variables are the only influencing factor for built environment design in which the building performance is the main driver ( $\mathrm{Li}$ et al., 2020). However, the sustainability paradigm shift is highly interconnected with the inclusion of social, economical, and environmental criteria, which require holistic consideration of the built environment as a system (Meadows et al., 1972a; Vester, 2012). In Introduction: Sustainable Building Design the UNEP report is used to figure out the global influence factors for sustainable building design. The building subsystem summarized in Table $\mathbf{1}$ in Introduction: Sustainable Building Design is further scrutinized by considering the key factors as a global variable list to define the built environment as a system as shown in Table 2, which is further analyzed to figure out critical leverage points and their interdependency.

Variable selection and understanding their role in the system is a major contribution from the design analysis. Therefore in a design research practice, the decision-making process is negotiable with the involved stakeholders (Vester, 2012; Jonas and German Narrative, 2018). However, such practice is relatively new and is rarely followed in building systems design where technical parameters still mostly define the built environment. Therefore using the UNEP as a reference point, system variables are screened in the Vester Sensitivity tool to check the roughly correct system image with the help of four aspects of the complex system and their eighteen specific indicators, which are described in Criteria Matrix: Variable Validation. Note that the UNEP report is an integration of different aspects of the built environment addressed by different authors, which suggests an integration of all ideas needs holistic consideration to define the built environment as a complete system that can function as a normative and roughly correct baseline system.

\section{Criteria Matrix: Variable Validation}

According to Vester, it is important to roughly know the system to correctly identify the leverage points, which can be possible if the defined variables fulfill the 18 indicators of the complex system by at least one variable (Vester, 2012). The variables identified so far in Table 2 were checked with the help of complex system criteria defining the building as a system instead of stakeholders defining the system variables. This follows the first layer variable test, which is subject to further scrutiny in 


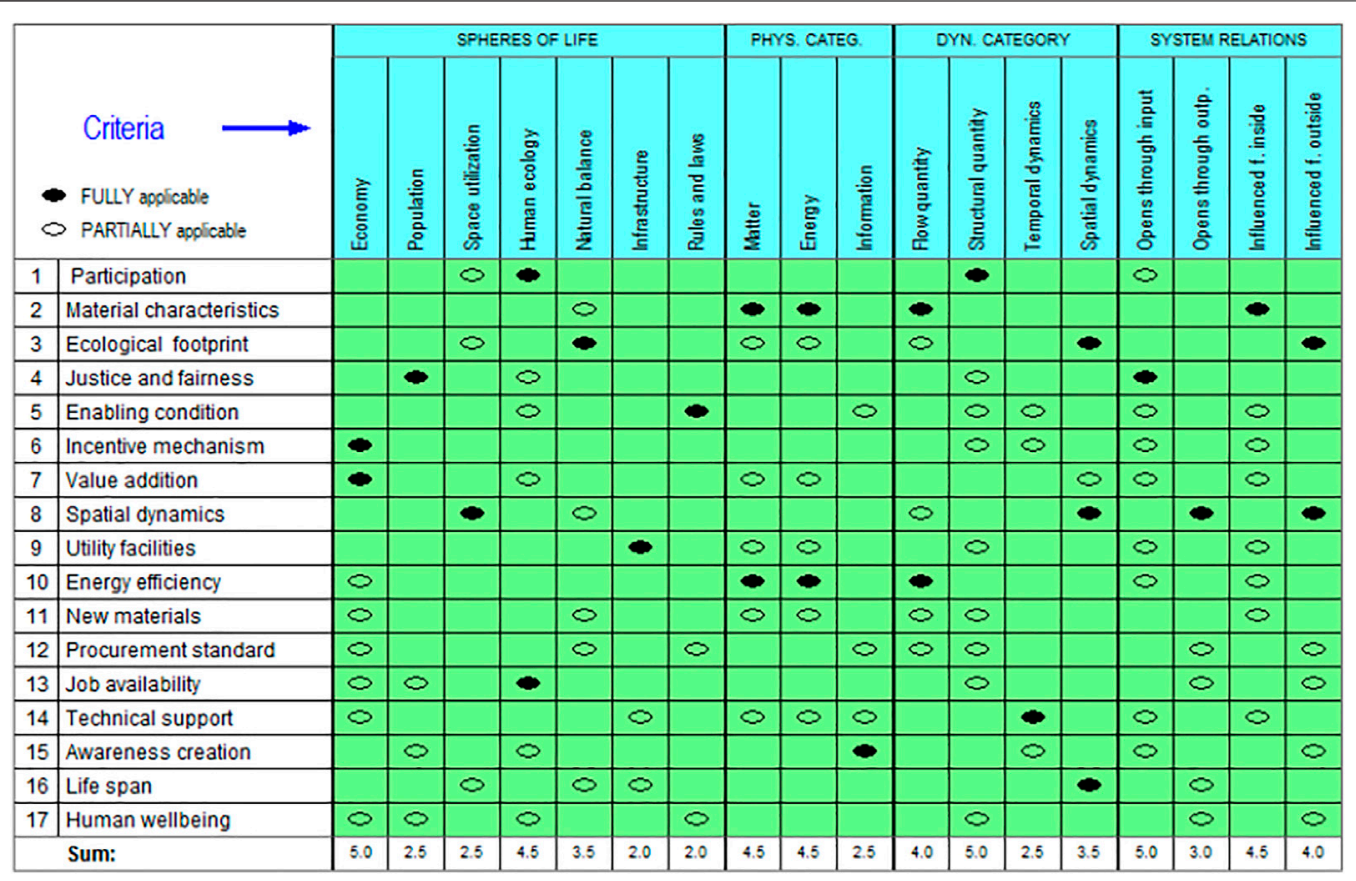

FIGURE 1 | Variable relevance test.

real-time negotiation. The 18 indicators are economy, population, space utilization, human ecology, natural balance, infrastructure, policies and laws, matter, energy, information, flow quantity, structural quantity, temporal dynamics, spatial dynamics, opens the system through input, opens the system through output, influence from inside, and influence from outside. The variable assessment is carried out using the criteria that were fulfilled fully or partially to define the system under consideration. This can be seen in Figure 1. For example, the variable Participation fulfills partially the "space utilization" criterion and "opens the system through input", whereas it fulfills fully the "human ecology" and "structural quantity" criteria. Stakeholder participation partially addressed the space use that "opens the system by input" as stakeholder engagement is crucial for allocating build environment space usage. Similarly, participation fulfills fully the "human ecology" and "structural quantity" criteria as they are the basis for system negotiation. This way, all the variables are screened for further scrutiny. Note that this screening is an independent justification by the observer, which will require stakeholder input and empirical testing. However, the variables screened at this stage provide a strong negotiation baseline for both stakeholder engagement and hypotheses for the empirical test. Since this is a first-of-itskind systems analysis, carrying out this stakeholder engagement and empirical test are beyond the scope of this study. In this way, the design of a building as a system is slightly different compared to formal practice in design research. However, the variables identified are subject to further refinement depending on the context that enables the stakeholder participation in the decision-making process instead of conducting a brainstorming workshop.
In Figure 1, seventeen building system variables are screened based on the 4 aspects of the complex system and the 18 indicators defining them (refer to Figure 1 for detail). The four aspects of a complex system are sphere of life, physical categories, dynamic categories, and system relevance (Vester, 2012). The sphere of life incorporates the seven essential aspects of a complex system defined by the following guiding questions (Vester, 2012; Vester, 2007a):

1) Who is there? (Population)

1) What are they doing? (Economy)

2) Where does it happen? (land use)

3) How do they feel? (Human ecology)

4) How appropriate is the exchange with the environment? (Natural balance)

5) What are the structure and ways of communication? (Infrastructure)

6) Which rules and laws are to be obeyed? (Communal life)

The identified global variables list in Table $\mathbf{2}$ in System Description: Global Variable Identification fulfills all those criteria. Therefore the current set of variables can become a starting point for the decision-making process for building as a system for future design and innovation projection.

\section{Impact Matrix: Variables Influence Factor and Cross-Impact Analysis}

Impact matrix is used for risk assessment in the management of any system for both technical and non-technical systems (Dumbravă and Iacob, 2013; Kassem et al., 2019). Therefore 


\section{Allocation of Values in the Influence Matrix}
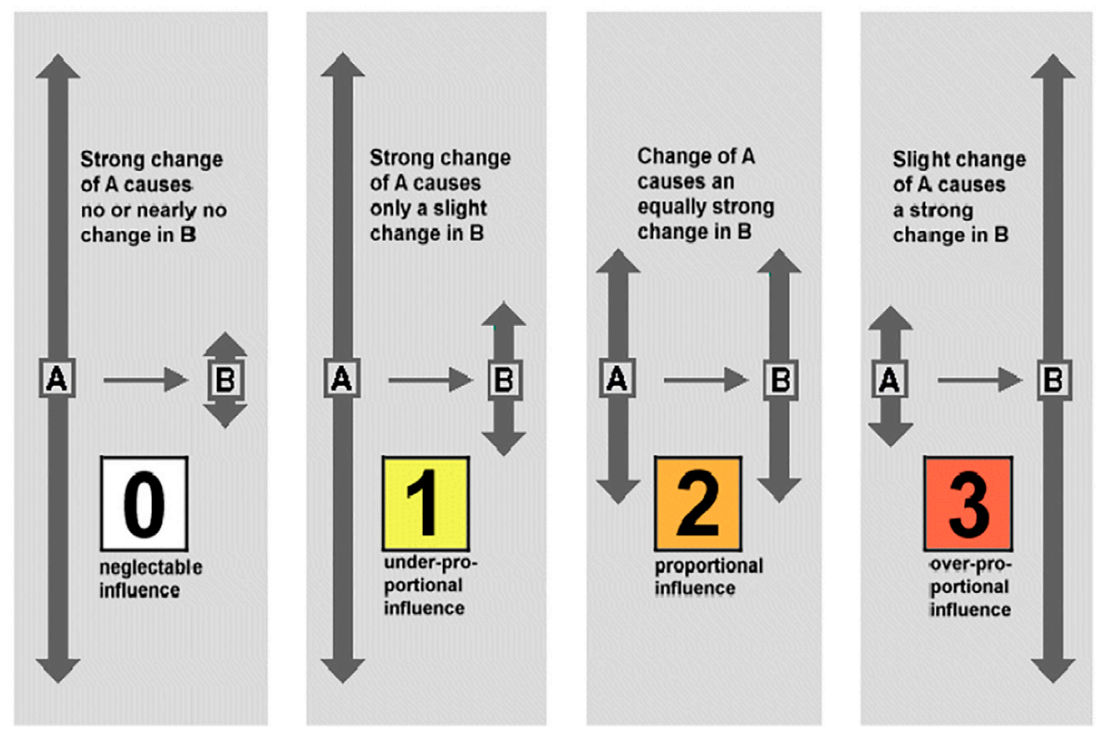

FIGURE 2 | Meaning of number values in impact matrix.

the impact matrix analysis is a simplified approach that enables the identification of future uncertainty and risk factors contained in the leveraging variable according to the Vester Sensitivity Model (Vester, 2012; Vester, 2007a).

The impact matrix is evaluated with the help of discrete values defining the variable influence strength as shown in Figure 2 (Vester, 2012; Vester, 2007a). The influencing strength of variables is directional meaning that if the variable has a bidirectional influencing effect then it generates a feedback effect, which will be elaborated in Effect System of the Built Environment as a System.

The influence factor of the global variables is contextual, which is an important condition for the design of built environment in contrast to generalized technical standard practice (Vester, 2012; Vester, 2007a). Therefore the discrete values assigned to the variables are subject to refinement for site-specific projects and types of building systems. Here the global variable list is used to identify the system leverage potential for built environment design consideration in general as shown in Figure 3. The numerical values attributed to variables indicate the system influencing strength defined by Active sum, Passive sum, $\mathrm{P}$-value, and Q-value. The active sum is an aggregate of horizontal numerical attributes that the overall influencing strength of the variables will have on the system. The passive sum is an aggregate of the vertical numerical attributes where the variables are influenced by the system. The $\mathrm{P}$-values are the product of the active sum and passive sum. The Q-values are the quotient of the Active sum and the Passive sum multiplied by 100. These P-values and Q-values are used for strategic positioning of the variables in the system. Note that this process needs stakeholder participation for user-centric decision support. Since the user-centric decision is contextual, the current assessment is purely observer justification and should be used as a hypothetical research result. Furthermore, the assignment of points for influencing effect differs from situation to situation and context to context. However, the current assessment provides the baseline for the built environment as a complete system for further negotiation.

\section{The Role Variables Play in the System}

The numerical attributes of the variables, which are assigned based on the impact matrix score in Impact Matrix: Variables Influence Factor and Cross-Impact Analysis define the role of variables in the system. The variables can occupy any one of the 50 different strategic field defined by the P-values and Q-values of the variables in the strategic two-dimension plot as shown in Figure 4.

The strategic field, which is divided into 50 different, areas carries a unique strategic statement to define the role of each variable in the system (Gallen, 2006). The strategic statement according to Vester is based on real-time project experience from over 30 years and it is based on bio-cybernetic theories (Vester, 2012; Vester, 2007a; Gallen, 2006). The strategic statements of the built environment variables are in Table 3.

The strategic position of variables in Figure 2 and their strategic statement in Table 3 define the role of the variable in the system. Many critical conclusions can be drawn from this analysis. For example the variables occupying the active region indicate they are likely to act as a system change lever, the variables occupying the reactive region indicate they are likely to act as a system indicator, the variables occupying the critical region indicate they are likely to leverage the system and the variables occupying the buffering region indicate they are neutral and are suitable for feedback control for corrective action. The 


\begin{tabular}{|c|c|c|c|c|c|c|c|c|c|c|c|c|c|c|c|c|c|c|c|c|}
\hline & Influence by $\neq$ to $\longrightarrow$ & 1 & 2 & 3 & 4 & 5 & 6 & 7 & 8 & 9 & 10 & 11 & 12 & 13 & 14 & 15 & 16 & 17 & \multicolumn{2}{|c|}{ AS $P$} \\
\hline 1 & Participation & $\mathrm{X}$ & 0 & 1 & 2 & 1 & 0 & 0 & 0 & 0 & 1 & 2 & 2 & 0 & 0 & 2 & 0 & 1 & 12 & 132 \\
\hline 2 & Material characteristics & 0 & $\mathrm{x}$ & 3 & 0 & 0 & 0 & 2 & 0 & 2 & 2 & 2 & 0 & 0 & 0 & 0 & 2 & 2 & 15 & 270 \\
\hline 3 & Ecological footprint & 0 & 1 & X & 0 & 1 & 0 & 0 & 0 & 0 & 1 & 1 & 1 & 0 & 0 & 0 & 1 & 2 & 8 & 240 \\
\hline 4 & Justice and fairness & 2 & 0 & 1 & $\mathrm{x}$ & 2 & 1 & 2 & 0 & 2 & 0 & 3 & 1 & 2 & 0 & 1 & 0 & 3 & 20 & 340 \\
\hline 5 & Enabling condition & 2 & 2 & 2 & 2 & $\mathrm{X}$ & 2 & 3 & 1 & 1 & 2 & 2 & 1 & 1 & 1 & 1 & 0 & 2 & 25 & 650 \\
\hline 6 & Incentive mechanism & 1 & 1 & 2 & 2 & 2 & $x$ & 2 & 1 & 1 & 2 & 3 & 1 & 0 & 1 & 0 & 1 & 2 & 22 & 198 \\
\hline 7 & Value addition & 1 & 1 & 1 & 1 & 3 & 2 & $x$ & 0 & 1 & 1 & 2 & 1 & 2 & 0 & 1 & 1 & 2 & 20 & 400 \\
\hline 8 & Spatial dynamics & 0 & 0 & 3 & 0 & 1 & 0 & 0 & $\mathrm{X}$ & 0 & 0 & 0 & 1 & 0 & 0 & 0 & 2 & 2 & 9 & 72 \\
\hline 9 & Utility facilities & 0 & 0 & 1 & 2 & 2 & 0 & 0 & 0 & $\mathrm{X}$ & 3 & 1 & 0 & 1 & 1 & 0 & 0 & 2 & 13 & 208 \\
\hline 10 & Energy efficiency & 0 & 2 & 3 & 0 & 2 & 1 & 2 & 0 & 2 & $X$ & 2 & 2 & 1 & 1 & 1 & 2 & 1 & 22 & 508 \\
\hline 11 & New materials & 1 & 3 & 2 & 1 & 2 & 1 & 2 & 0 & 2 & 2 & $x$ & 2 & 1 & 1 & 1 & 2 & 2 & 25 & 725 \\
\hline 12 & Procurement standard & 0 & 3 & 2 & 1 & 2 & 2 & 1 & 2 & 1 & 2 & 2 & x & 1 & 1 & 0 & 2 & 2 & 24 & 360 \\
\hline 13 & Job availability & 0 & 0 & 0 & 3 & 2 & 0 & 2 & 0 & 0 & 0 & 2 & 0 & X & 0 & 1 & 0 & 2 & 12 & 168 \\
\hline 14 & Technical support & 2 & 2 & 2 & 0 & 2 & 0 & 1 & 1 & 2 & 2 & 2 & 1 & 2 & $\mathrm{x}$ & 2 & 2 & 1 & 24 & 144 \\
\hline 15 & Awareness creation & 2 & 2 & 2 & 2 & 2 & 0 & 1 & 1 & 2 & 2 & 3 & 1 & 1 & 0 & $\mathrm{X}$ & 2 & 1 & 24 & 264 \\
\hline 16 & Life span & 0 & 1 & 3 & 1 & 1 & 0 & 2 & 2 & 0 & 1 & 2 & 1 & 2 & 0 & 0 & $x$ & 1 & 17 & 289 \\
\hline 17 & Human wellbeing & 0 & 0 & 2 & 0 & 1 & 0 & 0 & 0 & 0 & 2 & 0 & 0 & 0 & 0 & 1 & 0 & X & 6 & 168 \\
\hline & & 11 & 18 & 30 & 17 & 26 & 9 & 20 & 8 & 16 & 23 & 29 & 15 & 14 & 6 & 11 & 17 & 28 & PS & \\
\hline & & 109 & 83 & 27 & 118 & 96 & 244 & 100 & 112 & 81 & 96 & 86 & 160 & 86 & 400 & 218 & 100 & 21 & & 100 \\
\hline
\end{tabular}

FIGURE 3 | Cross impact analysis.

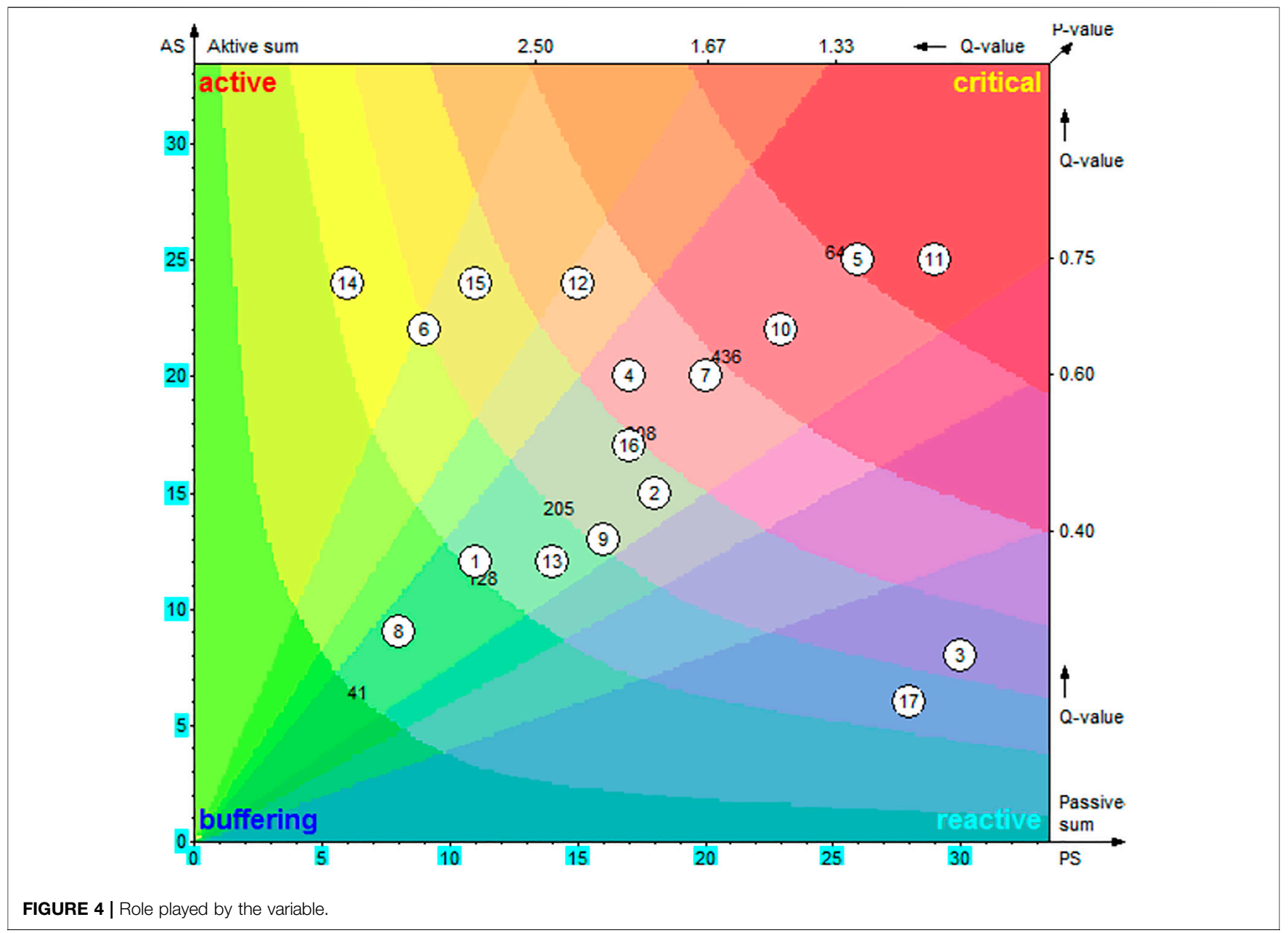


TABLE 3 | Strategic statement of the variables in two-dimensional plots.

\begin{tabular}{|c|c|c|c|}
\hline SIno & Global variable & Strategic statement of & Role played \\
\hline 1 & Participation & $\begin{array}{l}\text { Slightly reactive and weakly buffering component which is contributing to the self-regulation of the system } \\
\text { without being an indicator }\end{array}$ & Strong feedback control \\
\hline 2 & $\begin{array}{l}\text { Material } \\
\text { characteristics }\end{array}$ & $\begin{array}{l}\text { Neutral section between active, reactive, buffering, and critical. There are few means to steer the system via the } \\
\text { components of this area which are, on the other hand, well suited for self-regulation if integrated into feedback } \\
\text { cycles }\end{array}$ & Strong feedback control \\
\hline 3 & Ecological footprint & $\begin{array}{l}\text { Easily movable component compensating many interventions because of its integration in feedback cycles. } \\
\text { Caution advised if connected to active or critical components because in this case, an intervention may easily } \\
\text { destabilize the system }\end{array}$ & Strong system Indicator \\
\hline 4 & Justice and fairness & $\begin{array}{l}\text { Interventions in components of this section often cause pendulum-like movements which may compensate } \\
\text { premature corrections in the system. Control of this self dynamic (which may stop a desired development) would } \\
\text { be better carried out from outside the system }\end{array}$ & Weak feedback control \\
\hline 5 & Enabling condition & $\begin{array}{l}\text { The strong influence of this component on the rest of the system can be both greatly strengthened or completely } \\
\text { collapsed by strong positive feedback. Beware of oversteering }\end{array}$ & $\begin{array}{l}\text { Strong leveraging } \\
\text { variable }\end{array}$ \\
\hline 6 & Incentive mechanism & $\begin{array}{l}\text { Weakly buffering and more active than reactive, this component is a good lever to undertake interior corrections. } \\
\text { It might be necessary to operate it repeatedly }\end{array}$ & Change lever \\
\hline 7 & Value addition & $\begin{array}{l}\text { Interventions in components of this section often cause pendulum-like movements which may compensate } \\
\text { rather soon corrections in the system. Control of this self-dynamic (which may stop a desired development) } \\
\text { would be better carried out from outside the system }\end{array}$ & Weak feedback control \\
\hline 8 & Spatial dynamics & $\begin{array}{l}\text { A typical buffering component with little action or reaction. It may help to stabilize the system (elastic stability) via } \\
\text { self-regulation (if it is not a hidden activator while influencing a critical variable) }\end{array}$ & Strong feedback control \\
\hline 9 & Utility facilities & $\begin{array}{l}\text { Neutral section between active, reactive, buffering, and critical. There is little means to steer the system via the } \\
\text { components of this area which are on the other hand well fitted for self-regulation if integrated into feedback } \\
\text { cycles }\end{array}$ & Strong feedback control \\
\hline 10 & Energy efficiency & $\begin{array}{l}\text { Changing this critical component may cause trouble because of its equally strong activity and reaction. If not } \\
\text { intended to give a strong initial impact it has to be bound in feedback cycles when modified }\end{array}$ & Leveraging variable \\
\hline 11 & New materials & $\begin{array}{l}\text { The strong influence of this component on the rest of the system can be both greatly strengthened or completely } \\
\text { collapsed by strong positive feedback. Beware of oversteering }\end{array}$ & $\begin{array}{l}\text { Strong leveraging } \\
\text { variable }\end{array}$ \\
\hline 12 & $\begin{array}{l}\text { Procurement } \\
\text { standard }\end{array}$ & $\begin{array}{l}\text { A slightly active and slightly critical variable, suitable for moderate steering. Although the effect can be } \\
\text { strengthened or weakened by repercussions from the system it cannot tip over nor will it be compensated right } \\
\text { away }\end{array}$ & Weak leveraging variable \\
\hline 13 & Job availability & $\begin{array}{l}\text { Slightly reactive and weakly buffering component which is contributing to the self-regulation of the system } \\
\text { without being an indicator }\end{array}$ & Strong feedback control \\
\hline 14 & Technical support & $\begin{array}{l}\text { Considerably active lever. Its use, however, can produce unintended changes. Therefore the side effects have to } \\
\text { be analyzed }\end{array}$ & Strong change lever \\
\hline 15 & Awareness creation & $\begin{array}{l}\text { Active variable whose modification may get things going. However, to obtain a lasting influence it should be } \\
\text { protected against the immanent compensation of the system or strengthened by concerted action with } \\
\text { components acting in the same direction }\end{array}$ & Weak change lever \\
\hline 16 & Life span & $\begin{array}{l}\text { Neutral section between active, reactive, buffering, and critical. There is little means to steer the system via the } \\
\text { components of this area which are on the other hand well fitted for self-regulation if integrated into feedback } \\
\text { cycles }\end{array}$ & Strong feedback control \\
\hline 17 & Human wellbeing & $\begin{array}{l}\text { Here you find components reflecting changes in the system (indicator). Because they are easily manipulable they } \\
\text { tend to interfere directly, thus blurring the situation and creating unexpected side effects }\end{array}$ & System Indicator \\
\hline
\end{tabular}

built environment as a system analysis indicates the global variables Human wellbeing and Ecological footprint as strong system indicators, Technical support as a strong change lever, and New materials and Enabling condition as strong system leveraging variables. The leveraging variables are however subject to many unintended side effects, which need to be taken into consideration for the success conditions of any sustainable built environment design in the future. This is further analyzed in Effect System of the Built Environment as a System.

\section{Effect System of the Built Environment as a System}

Effect system of the variables is a simplified representation of impact matrix to enable networked thinking in a complex problem, which is based on the graph theory (Bondy and
Murty, 1976). The model representation of the built environment with the help of system variables that define the built environment and their critical influence factor can enable holistic decision support when it is observed in a network of influencing effects as shown in Figure 5.

The model representation of Figure $\mathbf{5}$ has two sets of influencing effects: the set with equal effects is represented by a continuous line connecting the variables, and the other set with the opposite effect is represented by a dotted line connecting the variables. The line connecting the variables carries descriptive reasoning, which can be communicated with the involved stakeholder for the design of the built environment as a system. On the other hand, causality verification of the network link is a never-ending inquiry that means the model can generate a new research hypothesis continuously depending on the context. At this stage, a valuable comparative conclusion can be drawn from the effect system construction, which can be 


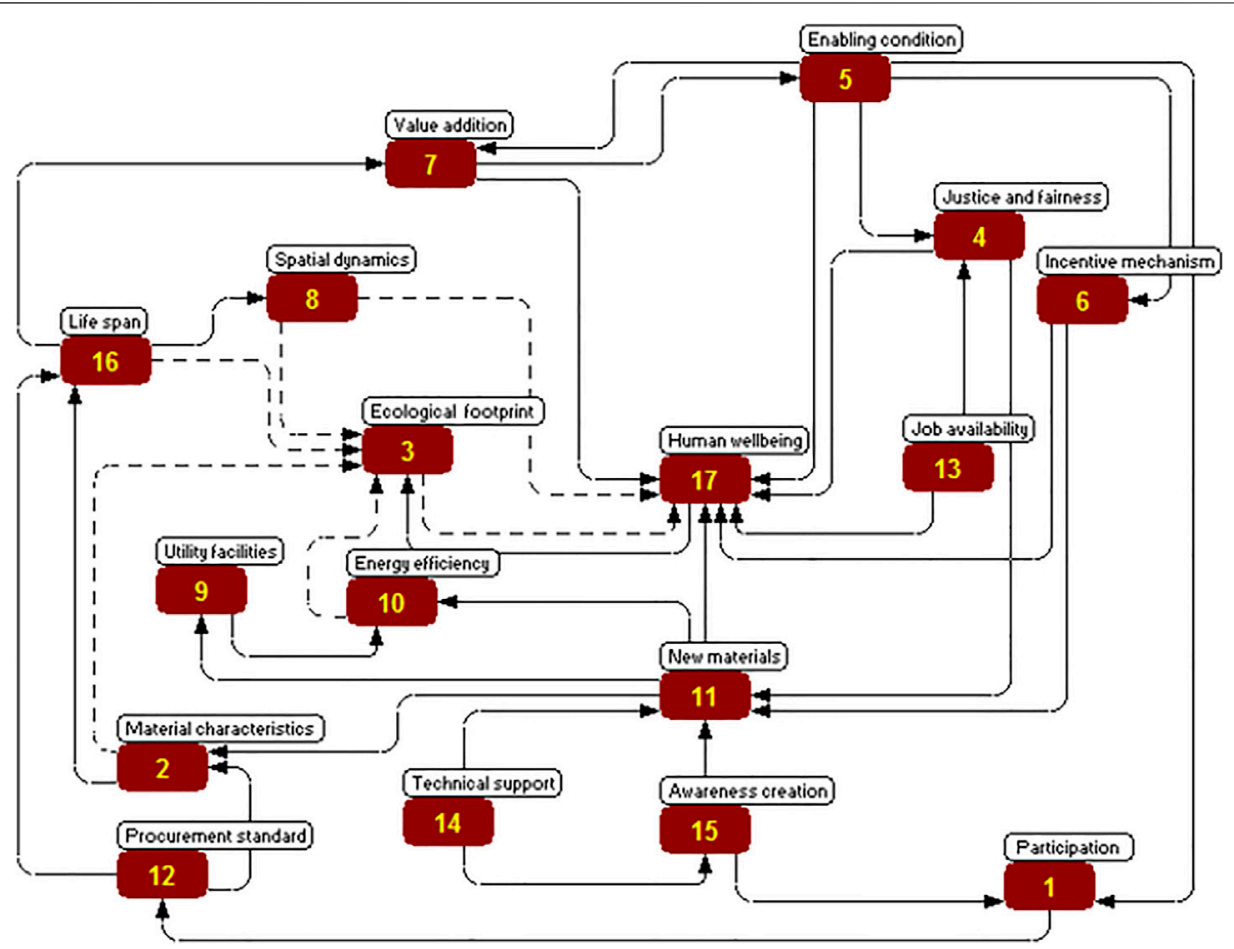

FIGURE 5 | Effect system of the variables.

compared with the natural system according to Vester (2012). The human and natural systems are part of the built environment, which requires process control based on clear future path identification (Robinson et al., 2018). This aspect has been well addressed by Vester (2012) by introducing the concept of positive and negative feedback effects. The manmade system is very closely related to the natural system if it has to be sustainable, where the positive feedback is accompanied by negative feedback. This also defines to some extent the meaning of the sustainability paradigm as reflected in the evolution of design in sustainability science (Ceschin and Gaziulusoy, 2016). The positive feedback is a continuous growth cycle, having reinforcing equal effect whereas the negative feedback is a controlled growth cycle, having reinforcing opposite effects (Vester, 2012). The model representation of the built environment in Figure 5 has this positive and negative feedback effect for system growth and control condition as follows:

Positive feedback effect.

1) $5 \rightarrow 7 \rightarrow 5$ : Feedback between Enabling condition and Value addition

2) $1 \rightarrow 12 \rightarrow 16 \rightarrow 7 \rightarrow 5 \rightarrow 1$ : Feedback between Participation, Procurement standards, Life span, Value addition, and Enabling condition

3) $1 \rightarrow 12 \rightarrow 2 \rightarrow 16 \rightarrow 7 \rightarrow 5 \rightarrow 1$ : Feedback between Participation, Procurement standards, Material Characteristics, Life span, Value addition, and Enabling condition
4) $2 \rightarrow 16 \rightarrow 7 \rightarrow 5 \rightarrow 4 \rightarrow 11 \rightarrow 2$ : Feedback between Material Characteristics, Life span, Value addition, Enabling condition, Justice and fairness, New material

5) $2 \rightarrow 16 \rightarrow 7 \rightarrow 5 \rightarrow 6 \rightarrow 11 \rightarrow 2$ : Feedback between Material Characteristics, Life span, Value addition, Enabling condition, Incentive mechanism, New material

Negative feedback effect.

1) $3 \rightarrow 17 \rightarrow 3$ : Feedback effect between Ecological footprint and Human wellbeing

A very important conclusion can be drawn from the above feedback effect identification. The impact matrix score of variables and their systemic role in Impact Matrix: Variables Influence Factor and Cross-Impact Analysis and The Role Variables Play in the System showed that the variables New material and Enabling condition are critical leveraging variables. However, they are directly in the feedback cycle with other system variables, which needs to be considered for the design of both new and retrofit built environments as a system. The feedback cycle gives rise to a unique scenario for the innovation projection, which can be used for stakeholder communication purposes.

\section{LIMITATION OF METHODOLOGY AND APPROACH IN MAINSTREAM SCIENTIFIC DISCIPLINE}

This study adopted design thinking as an alternative methodology for user-centric decision support, which is very 


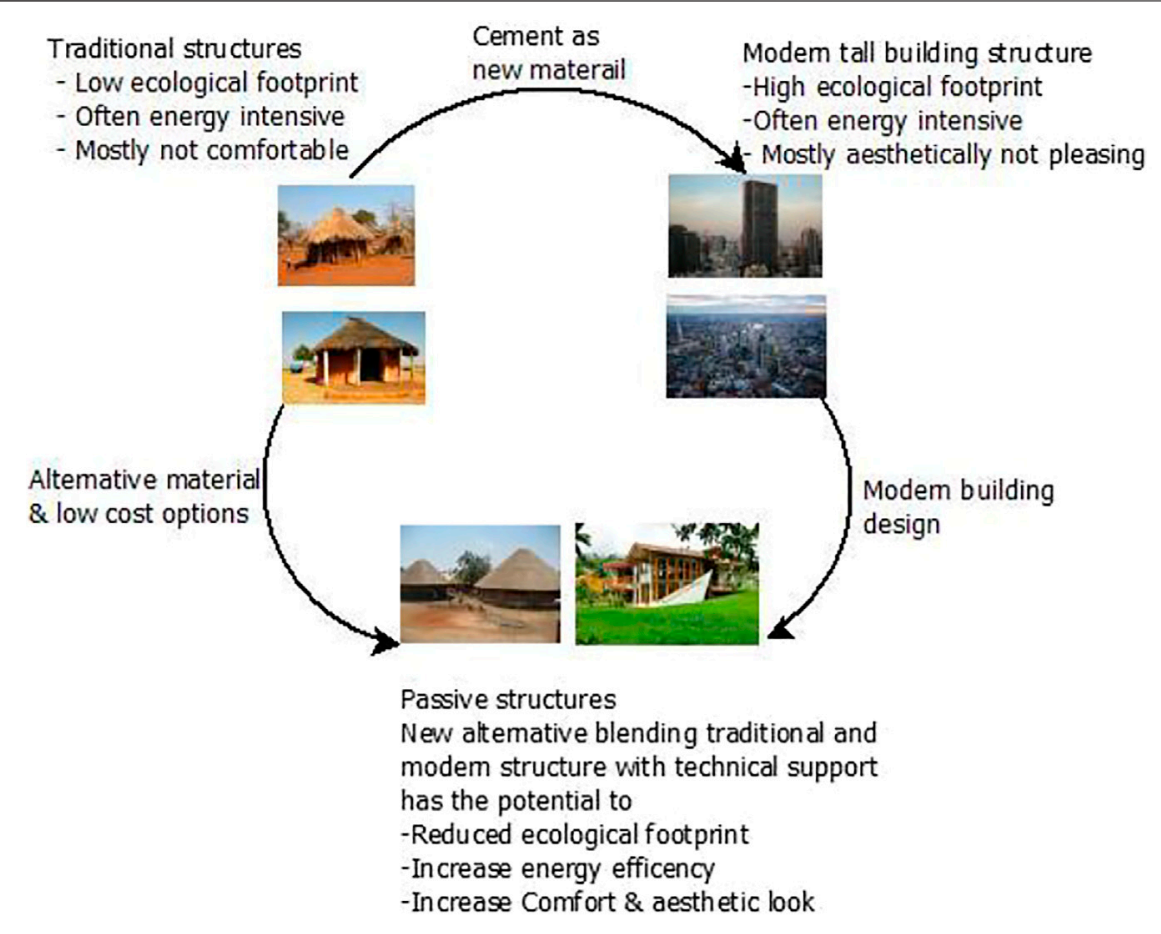

FIGURE 6 | Illustration and scoping the future using Wikipedia pictures.

rare. The concept of a living lab that intends to enable the sharing economy is an excellent example showing that user-centric decision support is meaningful (Wuppertal (2021). UrbanUp, 2021). The detail on research position and methodological overview can be seen in design thinking methodological consideration by Jonas and German Narrative (2018), Jonas (2007), Jonas et al. (2008). The extensive research requires stakeholder communication in a workshop environment, which is often not so easy. However such research endeavors seem to be much moreheavily required in sustainable system design, which is often communicative, philosophical, and requires stakeholders to address behavior correction rather than technical choice as an ultimate solution.

However, in this research, a major limitation can be seen in the lack of stakeholder participation throughout the process. An institution or community is an excellent stakeholding for built environment communication for the successful transition of the system to user-centric sustainable design considerations. Therefore this research review needs to be viewed as a baseline consideration, and a concrete conclusion cannot be drawn at this stage. Detailed built environment systems analysis requires scenario projection for a sustainable future. This article can provide a substantial baseline for the built environment from the design perspective although technical and empirical testing are critical requirements for the success of sustainable design. The initial basic discussion and case study relating to institutional engagement for system negotiation is exemplified in Discussion. However, such a case is very rare to make a comparative study. For example, the living lab design of a zero-emission campus for Trier University of applied science is a first of its kind campus evolved from community participation (refer to Figure 7 and the text) in a European context. This exemplary case can be re-evaluated to educate us on sustainable development which also enables built environment design considerations as part of a holistic system.

\section{RESULT}

The earlier review that introduced the different perspectives addressed in the UNEP report seems to show deficiency to describe the built environment as a system. However, in recent years emerging approaches such as Multi-Criteria Decision Making (MCDM) methods, a multi-disciplinary PerformanceBased Design (PBD), holistic energy performance certification scheme of retrofit building design and Systematic Reviews and Meta-Analyses (PRISMA) involving key performance indicators have to some extent addressed the systemic review on the built environment as a system (Passoni et al., 2021; Ho et al., 2021). However, the analysis of the built environment as a system in recent development shows clearly that the technology-dominated decision field seems to be the priority. As this review article, which addresses systems analysis, indicates, technology is only achange lever that does not necessarily provide a desirable sustainable solution to built environment challenges. Therefore, good enabling conditions are critical for the penetration of technology as a change lever for the design of a sustainable built environment. The blending of modern building and mimicing conventional building design seems valuable for the system transition to sustainable material choices and 


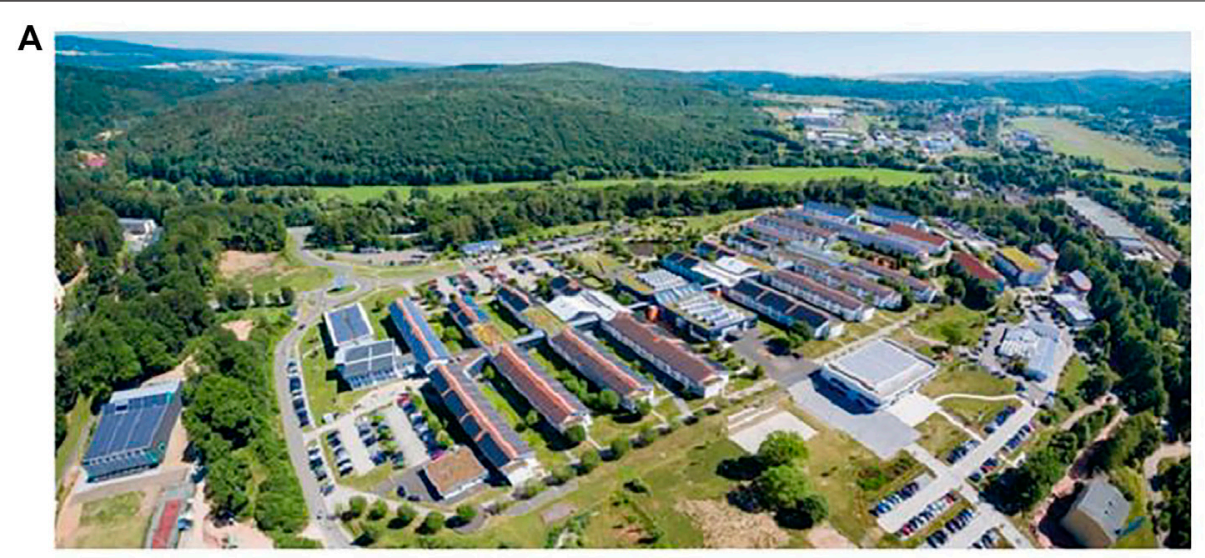

B
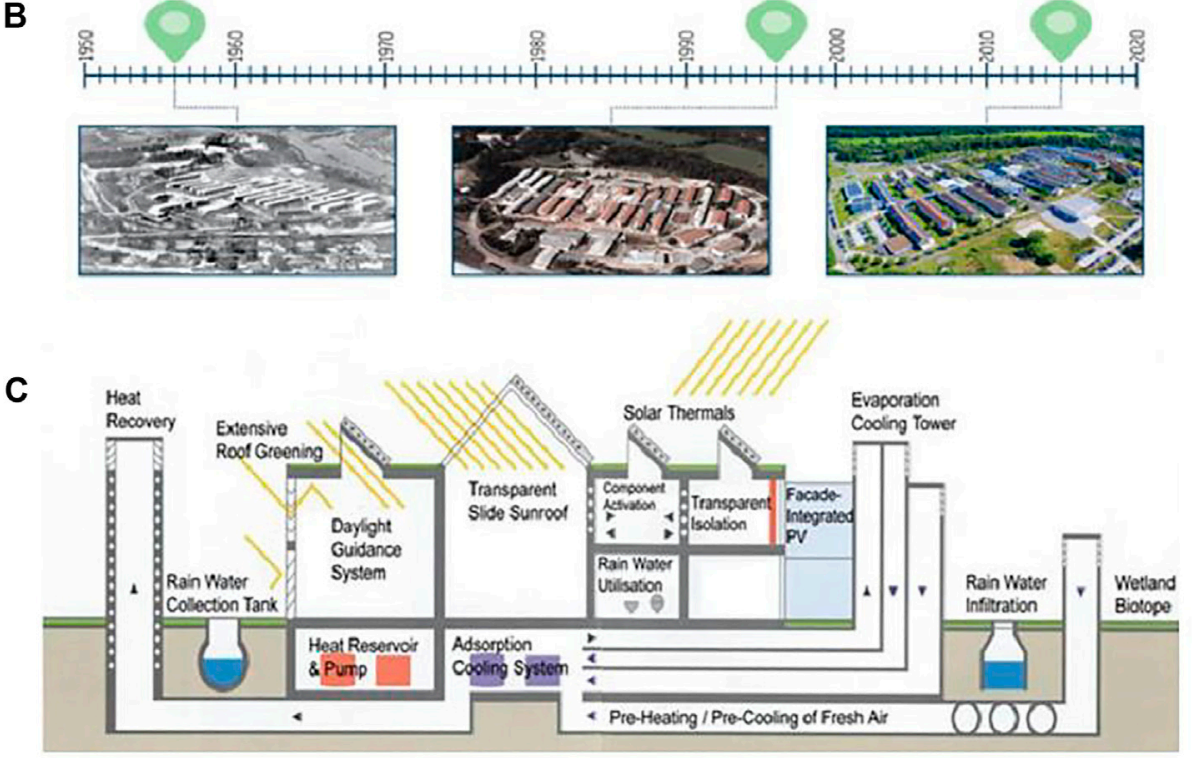

FIGURE 7 | Zero-emission campus as a living lab the systemic approach (Heck et al., 2021).

technology, which requires negotiation rather than fixed-for-all single standard designs. This can only address the business vision and not necessarily the de-growth strategy, which was the initial message from the club of Rome publication concerning the global systems transition to a more resilient and sustainable system. The de-growth strategy will mostly require functional value definition of build environment as a system that integrates social, cultural, economical, and environmental values, which is rather contextual. Integration of such values cannot be projected based on the technological problem statement but more by investigation of systems through negotiation with involved stakeholders. There is a major question to be asked to that concern: will the built environment be designed for urbanization or regionalization? Therefore the approach adopted in this research analysis suggests that user-centric negotiation is critical. Sustainable development is a global target to reduce consumerist behavior that requires a strong alignment of user behavior to support the available alternatives to orient a systems design that aims for a de-growth vision. Since the built environment contributes a large share of human needs, sustainable building design could be one of the many ways to initialize a de-growth strategy. However, it will require an extensive negotiation process involving community and decision-makers in a largely holistic approach.

Therefore, this research review contributes to defining the built environment as a roughly correct system image that will potentially address the re-orientation of future visions and road map development and to enable extensive negotiation based on the selected global variable list to define the built environment as a system. The vision development can only be visualized in a cybernetic pattern, as the built environment is linked to other systems rather than only focusing on technology as the ultimate change agent. Therefore re-alignment of target vision is critical for sustainable design of the built environment in the future horizon, and it is not yet known even whather the prediction of urban growth has influenced built environment systems design to be aligned to a sustainable system. Therefore the systems analysis of the built environment with the inclusion of a global variables 
list in this study gives a clear hint on system re-orientation for the success of a sustainable development vision. The following are the key results that can be noted from th review of the built environment as a system in this research review article:

1. Life cycle assessment is an excellent tool but it has its own limitation concerning the accuracy of the eco-invent database, which is usually normalized. The study of the built environment as a system based on the LCA approach will lead to the unlimited assumption of data and has the potential to generate precisely the wrong result. Therefore this review suggests the use of LCA has to be limited to single products rather than a complete system.

2. Researchers still debate on a single problem cycle that has been addressing the linear throughput system even if three aspects (social, economic, and environmental) of a sustainable development goal are captured. Unless the global variable is defined clearly depending on the context, sustainability justification is like a street light concept of finding a solution in a problem where the solution might be outside of the defined problem cycle. Therefore, the global variables are negotiable and this study provides to some extent the baseline condition for negotiation, which is contextual.

3. The emerging idea of the system change lever defined by technology transformation is simply not sufficient to address many different critical needs such as resiliency, structural safety, cultural aesthetic requirements, and above all the user acceptability for the transformation.

Considering all the critical findings from the review of the UNEP and recent publications, this study may be used as a baseline framework for sustainable built environment policy choices defined by the global variables. Since this study is a research review, the actual system inquiry will have significantly higher normative values to be considered in addition to the system defining global variables suggested in this review. Therefore, it has to be noted that there are major limitations in this research, as stakeholder negotiation is missing and that is the suggested method for built environment design for system transformation. The study is very useful for the design of the built environment system and the associated policy re-alignment required to enable the system transformation to selfsustainable growth projection in the future.

\section{DISCUSSION}

From the analysis of the built environment as a system in Built Environment Systems Analysis Using Vester Sensitivity Model, System Description: Global Variable Identification, Criteria Matrix: Variable Validation, Impact Matrix: Variables Influence Factor and Cross-Impact Analysis, The Role Variables Play in the System, and Effect System of the Built Environment as a System, it is clear that the holistic built environment design is a negotiable endeavor. However, the negotiation has to enable the de-growth projection and to decouple the ecological footprint from the human consumerism trend to address sustainable development. Thus, sustainable development goals are philosophical ideologies, even if the techno-environmental consideration is the driving force for their development. The system inquiry indicates New Material and Enabling conditions as critical system leveraging global variables, where the variable Technical support acts as system change lever and the indicator variables Human wellbeing and Ecological footprint define the leverage condition (refer to Figure 4 The Role Variables Play in the System). The historical growth trend of these variables is visualized in Figure 6 as a normative projection.

In Figure 6 the current move to sustainable development is curtailing the need to reexamine the past and to perform a backcasting strategy for the future. In this context, although the quality and lifespan of traditional buildings are not up to the modern building structure standards, it is super sustainable compared to modern concrete tall building structures even if the economic wellbeing can be expected from future tall building design. However, the intended target does not fulfill the degrowth strategy defined in the 1972 global system model projection for sustainable design (Meadows et al., 1972b). This ideology curtails the need for behavioral transformation addressing the success of systemic re-orientation, and addressing regionalization rather than urbanization. This is mainly due to the choice of construction material and the enabling environment that allowed and encouraged traditional buildings to be replaced by modern structures. This is also seen in the analysis of the built environment as a system where the global variables New material and Enabling condition are leveraging variables. Considering the feedback effect $2 \rightarrow 16 \rightarrow 7 \rightarrow 5 \rightarrow 6 \rightarrow 11 \rightarrow 2$ : Feedback between Material Characteristics, Life span, Value addition, Enabling condition, Incentive mechanism, New material, and the orientation of the built environment is influenced by many factors. The discovery of cement as a New Material enabled the construction of concrete structures, which is today known to be ecologically sustainable due to its longer lifespan. However, the growing urbanization further pushed the concrete structure to be tall, which is highly controversial and not sustainable in terms of energy demand, risk factors, and cost. To these growing challenges, new alternatives such as passive structures are a clear future for building sustainably. Passive structures are heavily influenced by building design and construction material choice. The currently available alternative building materials are shown in Table 4 for passive building design.

The availability of new material is however not as simple as it appears to be, which is highly influenced by Material Characteristics, Life span, Value addition, Enabling condition, and Incentive mechanism which indicates future challenges if these influencing effects are not recognized. In a way, observing the building as a system gives a holistic picture to identify challenges and opportunities arising from the list of variables defining their development. An example case of building as a system is shown in Figure 7 which represent the concept of a zero-emission campus in Germany (Heck et al., 2021; Hartard and teHeesen, 2016).

The sequential order of the zero-emission campus images in Figure 7 shows a) the current view, b) the historical development 
TABLE 4 | Alternative building materials.

\begin{tabular}{|c|c|c|c|c|}
\hline Material & Application & R-values (per inch) & RIS-values (per mm) & Source \\
\hline Rammed earth & Wall and floor & 0.4 & 0.07 & Windstorm and Schmidt (2013) \\
\hline Straw Bales & Wall and floor & $2.38-3.15$ & $0.42-0.55$ & Nehemiah Stone (2003) \\
\hline Bamboo & Wall, ceiling and floor & 0.96 & 0.17 & (Heatizon Systems, nd) \\
\hline Wool insulation & Wall and ceiling insulation & $3.5-3.8$ & $0.62-0.70$ & Roberts (2019) \\
\hline Tesla solar tiles & Roof substitute & - & - & Tesla (2020) \\
\hline Biocomposites & Wall, ceiling and floor & $3.46-3.58$ & $0.61-0.63$ & Hassanin et al. (2016) \\
\hline Mycelium & Wall, ceiling and floor & $1.8-4$ & $0.32-0.704$ & NEST (2019) \\
\hline Ecovative & Wall, ceiling and floor & $1.8-4$ & $0.32-0.704$ & NEST (2019) \\
\hline Bark siding & Natural beauty and wall insulation & 3.7 & 0.65 & Baca and Waugh (2020) \\
\hline Mass timber & Wall, floor, ceiling insulation & 1.25 & 0.22 & Glass et al. (2013) \\
\hline Grasscrete & Parking and Building surrounding & - & - & (Grasscrete, nd) \\
\hline Hempcrete & Wall, floor, ceiling and roof insulation & 2.4 & 0.423 & Hempcrete Insulation (2020) \\
\hline Recycled Plastic & Wall, floor, ceiling insulation & $4-8$ & $0.70-1.41$ & InspectAPedia (2020) \\
\hline Ferrock & Potential substitute for cement & - & - & Lanuza et al. (2017) \\
\hline Ashcrete & Road, bridges, and building surrounds & - & - & Ashcrete Technologies, (2020) \\
\hline Timbercrete & Wall and floor & $3-4$ & $0.53-0.704$ & Timbercrete Pty. Ltd (2015) \\
\hline
\end{tabular}

of the US military hospital to a zero-emission campus, and c) the technical features of the zero-emission campus design. The zeroemission campus located in the Birkenfeld district of RhinelandPalatinate is a building system exhibiting the living lab concept where passive building design, water-saving measures, energysaving measures, and rooftop solar photovoltaic are key to the zero-emission goal, which is a holistic system design that will address both education for sustainable development and campus as a study object (Heck et al., 2021; Hartard and teHeesen, 2016). The critical condition for the development, currently ranked greenest university in Germany and inEurope, is influenced by the global variables defining its development, where the old US military hospital was transformed to green campus (refer to Figures 7A-C sequence) (Heck et al., 2021; Hartard and teHeesen, 2016). The goal of the university is to achieve zeroemissions through the active participation of stakeholders from different disciplines, which is synergistically maintained for further progress and the idea of zero-emission philosophy. For example, the campus serves as an example test center for zeroemission community development by engaging the local municipalities with the university when designing the baseline choices for continuous improvement. Similarly, the integration of alternative insulation material, an electricity source from the PV system, and heat supplied from the Combined Heat and Power (CHP) bio-waste incineration plant are some key-value additions (Heck et al., 2021). Considering the case of the zero-emission campus as an example, the building design and retrofit system should be holistically addressed through global variables defining the built environment as a system rather than investigating single building design and retrofit in isolation. Thus the systemic approach can be used for community-level system design, which is an orientation and management challenge in contrast to already available building alternatives.

The critical aspect of innovation can be seen from the system transformation of building as a system, with retrofitted and upscaled utility facilities as an example case study of zero-emission campus design. The same approach can be applied in any retrofit project rather than individual building transformation in isolation. The system-level transformation is therefore an impactful innovation that can adequately address the sustainable design of the built environment. The building material listed in Table $\mathbf{4}$ is subject to product life cycle analysis rather than building as a process system. The built environment system comparison can then be made based on the embodied energy of building material and other associated impact categories. Furthermore, the built environment system's global variable list, effect system construction, and empirical qualification of influence factors are unending in their research scope as new scientific problem situations and hypotheses. Thus built environment as a system model representation is more holistic in addressing a sustainable paradigm shift for research practice and project choice. The idea of Vester-based system negotiation is adequately addressed in the design of Zero Emission Campus that integrates the community participation for university design. Currently, the campus engages the local community for any transformative process and innovative financing. The campus design is a baseline case for the municipalities as an applied research practice. The technology choice, process choice, and management choice can be easily replicated from the campus. However, such campus design is almost non-existent in most university environments. Therefore, this case study may be used as an existing study object for built environment design as a system. Note that this is an example case and does not necessarily reflect the actual operating conditions of different situations and contexts, which require an extensive stakeholder negotiation process.

\section{CONCLUSION}

This review research analysis gives meaningful insight for the stakeholder consultation process addressing the so-called living lab concept for sustainable built environment design. From the analysis of building as a system, it can be concluded that innovation potentials of the built environment can only be enabled by identifying the variables that will influence the 
system. Knowing roughly the correct system can be the basis for sustainable system transition requirements. User behavior correction seems to be missing in many sustainable design considerations. Often time the holistic assessment of the built environment is missing, where part of the building is prioritized in isolation in which the technological aspect dominates the decision field, which is a fundamental challenge for almost all the available sustainable solutions. The systemic challenges are applicable to the built environment, where user-centric decision support is critical. Based on the system theory and approaches applied to inquiry of the built environment, the following critical conclusions are noted:

1. Visualizing a built environment as a system is a complex process that involves large stakeholder participation and synergies which can be very contextual, and require robust negotiation.

2. Addressing sustainable development concerning built environment design is influenced not just by the single building but by the community as a whole, which requires a deeper understanding of the system defining global variables.

3. Building material choice is a systemic property and cannot be easily influenced by techno-economic value proposition. It requires both enabling conditions and user-centric decision

\section{REFERENCES}

Akadiri, P. O., Chinyio, E. A., and Olomolaiye, P. O. (2012). Design of A Sustainable Building: A Conceptual Framework for Implementing Sustainability in the Building Sector. Buildings 2, 126-152. doi:10.3390/ buildings 2020126

Ashcrete Technologies (2020). Municipal Solid Waste (MSW) Incineration Bottom Ash and Combined Ash Transformation. Available: http:// ashcretech.com/.

Asif, M., Dehwah, A., Ashraf, F., Khan, H., Shaukat, M., and Hassan, M. (2017). Life Cycle Assessment of a Three-Bedroom House in Saudi Arabia. Environments 4, 52. doi:10.3390/environments 4030052

Asif, M., Muneer, T., and Kelley, R. (2007). Life Cycle Assessment: A Case Study of a Dwelling home in Scotland. Building Environ. 42 (3), 1391-1394. doi:10.1016/ j.buildenv.2005.11.023

Baca, J., and Waugh, R. (2020). Thermal Properties of Poplar Bark. 1-12. Available: https://barkhouse.com/wp-content/uploads/2015/07/R-Value-BacaWaughPopular-Poplar-vBarkHouse.pdf.

Bakens, W. (2003). Realizing the Sector's Potential for Contributing to Sustainable Development. Available: http://www.uneptie.org/media/review/vol26no2-3/ voL26_no2-3.htm.

Behnam, N. (2017). A Review on Sustainable Building (Green Building). Int. J. Eng. Sci. 6 (1), 451-459. doi:10.5281/zenodo.267525

Ben, S. (2018). "Wicked Problems in Design and Ethics," in Systemic Design Theory, Methods, and Practice. Editor J. Peter (Tokyo: Springer), 119-139.

Bondy, J. A., and Murty, U. S. R. (1976). GRAPH THEORY WITH APPLICATIONS. NewYork,N.Y10017: ElsevierSciencePublishingCo., Inc.

Boonstra, C., and Pettersen, T. D. (2003). Tools for Environmental Assessment of Existing Buildings. Available: http://www.uneptie.org/media/review/vol26no23/voL26_no2-3.htm.

Brundtland, G. H. (1987). "Report of the World Commission on Environment and Development: Our Common Future," Oslo. Available: https:// sustainabledevelopment.un.org/content/documents/5987our-common-future.pdf.

Bunn, R. (2003). Sustainable Building Services in Developing Countries: the challenge to Find 'best-Fit' Technologies. Available: http://www.uneptie.org/ media/review/vol26no2-3/voL26_no2-3.htm. support, which is where the community plays an active role and makes choices valuable.

Therefore, design enquiries for a sustainable built environment require a much deeper negotiation process where decision-maker and takers engage in built environment design consideration. However, a conclusion cannot be drawn from this research as built environment design considerations require contextual case study. The variable list and the analysis conducted in this research can become the baseline for further research endeavors.

Built environment as a system is rare in the scientific literature, which is a very useful learning tool for built environment policy design and mainstream scientific research practice. However, due to time limitation stakeholder participation and real-world scenario consideration is still not fully covered in this study. Considering the rough system baseline from this research review article, different case studies can be further assessed, which is highly contextual for normative scenario projection.

\section{AUTHOR CONTRIBUTIONS}

The author confirms being the sole contributor of this work and has approved it for publication.

Ceschin, F., and Gaziulusoy, I. (2016). Evolution of Design for Sustainability: From Product Design to Design for System Innovations and Transitions. Des. Stud. 47, 118-163. doi:10.1016/j.destud.2016.09.002

Clift, M. (2003). Life-cycle Costing in the Construction Sector. Available: http:// www.uneptie.org/media/review/vol26no2-3/voL26_no2-3.htm.

Dumbravă, V., and Iacob, V.-S. (2013). Using Probability - Impact Matrix in Analysis and Risk Assessment Projects. J. Knowl. Manag. Econ. Inf. Technol., 76-91. Available: http://www.scientificpapers.org/wp-content/files/07_ Dumbrava_Iacob-USING_PROBABILITY_IMPACT_MATRIX_IN_ ANALYSIS_AND_RISK_ASSESSMENT_PROJECTS.pdf.

Edwards, S., and Bennett, P. (2003). Construction Products and Life-Cycle Thinking. Available: http://www.uneptie.org/media/review/vol26no2-3/ voL26_no2-3.htm.

EPA (2013). Sustainable Design and Green Building Toolkit. 2-99.

Force Sustainable Development Task (2003). Drivers for Sustainable Construction. Available: http://www.uneptie.org/media/review/vol26no2-3/voL26_no23.htm.

Gallen, St. (2006). Sensitivity Model Prof. Vester. Available: https://www.fredericvester.de/uploads/InformationEnglishSM.pdf.

Gausemeierand Management, Scenario. (1998). An Approach to Develop Future Potentials. Elsevier 59 (no. 2). doi:10.1016/S0040-1625(97)00166-2

Gaziulusoy, İ., and Erdoğan Öztekin, E. (2019). Design for Sustainability Transitions: Origins, Attitudes and Future Directions. Sustainability 11, 3601-3613. doi:10.3390/su11133601

Geyer, P., Stopper, J., Lang, W., and Thumfart, M. (2014). A Systems Engineering Methodology for Designing and Planning the Built Environment-Results from the Urban Research Laboratory Nuremberg and Their Integration in Education. Systems 2 (2), 137-158. doi:10.3390/systems2020137

Glass, S., Wang, J., Easley, S., and Finch, G. (2013). "Cross-Laminated Timber," in the U.S. Edition of the CLT Handbook, 1-55.

Grasscrete (nd). Grasscrete the Environmental Paving Solution. Available: https:// www.grasscrete.com/pdfs/brochures/GrasscreteBrochure.pdf.

Hartard, S., and te Heesen, H. (2016). "Environmental Campus Experience Green Technology.” Umwelt-Campus Birkenfeld. 1-14. Available: https://www. umwelt-campus.de/fileadmin/Umwelt-Campus/Oeffentlichkeitsarbeit/TechBroschuere/Broschuere-GrueneTechnologien-am-Campus-ENG-kleinWEB.pdf. 
Hassanin, A. H., Candan, Z., Demirkir, C., and Hamouda, T. (2016). Thermal Insulation Properties of Hybrid Textile Reinforced Biocomposites from Food Packaging Waste. J. Ind. Textiles 47 (6), 1024-1037. doi:10.1177/ 1528083716657820

Heatizon Systems (nd). Comparative R-Values of Building Flooring \& Subfloors. Available: https://www.heatizon.com/installation/r-values-building-flooring-subfloors.

Heck, P. (2021). "Small-Scale System Solutions-Material Flow Management (MFM) in Settlements (Water, Energy, Food, Materials)," in Sustainable Land Management In a European Context: A Co-design Approach. Editors T. Weith, T. Barkmann, N. Gaasch, S. Rogga, C. Strauß, and J. Zscheischler (Cham: Springer International Publishing), 269-289. doi:10.1007/978-3-03050841-8_14

Hempcrete Insulation (2020). Hemp Insulation R-Value \& U-Value Properties. Available: https://hempcretedirect.com/hempcrete-insulation/.

Ho, A. M. Y., Lai, J. H. K., and Chiu, B. W. Y. (2021). Key Performance Indicators for Holistic Evaluation of Building Retrofits: Systematic Literature Review and Focus Group Study. J. Building Eng. 43, 102926. doi:10.1016/j.jobe.2021.102926

Holger, W., and Buerkin, C. (2003). Concepts and Instruments for a Sustainable Construction Sector. Available: http://www.uneptie.org/media/review/ vol26no2-3/voL26_no2-3.htm.

Ifesi, A. (2003). Integration of EMS into National Regulatory Frameworks for Offshore Oil and Gas Production. Available: http://www.uneptie.org/media/ review/vol26no2-3/voL26_no2-3.htm.

InspectAPedia (2020). Free Encyclopedia of Building \& Environmental Inspection, Testing, Diagnosis, Repair. Available: https://inspectapedia.com/insulation/ Insulation-Values-Table.php.

Iyengar, K. (2015). Sustainable Architectural Design. England, UK: Routledge, 294.

Jonas, W. (2007). Design Research and its Meaning to the Methodological Development of the Discipline. Available: http://8149.website.snafu.de/ wordpress/wp-content/uploads/2011/07/2007_DRNow.pdf.

Jonas, W., and German Narrative, A. (2018). Systems Design Thinking: Theoretical, Methodological, and Methodical Considerations. Germany: Springer book publication.

Jonas, W., Morelli, N., and Munch, J. (2008). Designing a Product Service System in a Social Framework: Methodological and Ethical Considerations. Available: http://shura.shu.ac.uk/526/.

Scotland, J. (2012). Exploring the Philosophical Underpinnings of Research: Relating Ontology and Epistemology to the Methodology and Methods of the Scientific, Interpretive, and Critical Research Paradigms. Elt. 5, 9. doi:10.5539/elt.v5n9p9

Kassem, M. A., Khoiry, M. A., and Hamzah, N. (2019). Using Probability Impact Matrix (PIM) in Analyzing Risk Factors Affecting the success of Oil and Gas Construction Projects in Yemen. Ijesm 14 (3), 527-546. doi:10.1108/IJESM-032019-0011

Kibert, C. J. (2003). Deconstruction: the Start of a Sustainable Materials Strategy for the Built Environment. Available: http://www.uneptie.org/media/review/ vol26no2-3/voL26_no2-3.htm.

Kohler, N., and Moffatt, S. (2003). Life-cycle Analysis of the Built Environment. Available: http://www.uneptie.org/media/review/vol26no2-3/voL26_no23.htm.

Lanuza, A., Achaiah, A. T., Bello, J., and Donovan, T. (2017). FERROCK: A LIFE CYCLE COMPARISON TO ORDINARY PORTLAND CEMENT. 1-24. Available: http://ironkast.com/wp-content/uploads/2017/11/USC-FerrockFinal-Paper-4.24.17.pdf.

Li, S., Liu, L., and Peng, C. (2020). A Review of Performance-Oriented Architectural Design and Optimization in the Context of Sustainability: Dividends and Challenges. Sustainability 12 (4), 1427. doi:10.3390/su12041427

McDonough, W., and Braungart, M. (2003). Towards a Sustaining Architecture for the 21 St century: the Promise of Cradle-To-Cradle Design. Available: http:// www.uneptie.org/media/review/vol26no2-3/voL26_no2-3.htm.

Meadows, D. H., Meadows, D. L., Randers, J., and Behrens Ill, W. W. (1972). Limits to Growth. Falls Church,Virginia, United States: Potomac Associates, 205.

Meadows, W. W., Donella, H., Dennis, L. Meadows., Randers, Jorgen., and Behrens (1972). The Limits to Growth. New York: Club of Rome.

Model, M. S. (2014). The Computerized System Tools for a New Management of Complex Problems. Available: https://www.frederic-vester.de/uploads/ InformationEnglishSM.pdf.
Nehemiah Stone (2003). Thermal Performance of Straw Bale Wall Systems. 1-7. Available: https://www.ecobuildnetwork.org/.

NEST (2019). Next Evolution in Sustainable Building Technologies (NEST). Available: https://www.empa.ch/web/nest.

Oregi, X., Hernandez, P., Gazulla, C., and Isasa, M. (2015). Integrating Simplified and Full Life Cycle Approaches in Decision Making for Building Energy Refurbishment: Benefits and Barriers. Buildings 5, 354-380. doi:10.3390/ buildings5020354

Passoni, C., Marini, A., Belleri, A., and Menna, C. (2021). Redefining the Concept of Sustainable Renovation of Buildings: State of the Art and an LCT-Based Design Framework. Sustainable Cities Soc. 64, 102519. doi:10.1016/ j.scs.2020.102519

Pavlović, B., Ivezić, D., and Živković, M. (2021). State and Perspective of Individual Household Heating in Serbia: A Survey-Based Study. Energy and Buildings 247, 111128. doi:10.1016/j.enbuild.2021.111128

Ramírez-Villegas, R., Eriksson, O., and Olofsson, T. (2019). Life Cycle Assessment of Building Renovation Measures-Trade-Off between Building Materials and Energy. Energies 12 (3), 344. doi:10.3390/en12030344

Riley, D., Pexton, K., and Drilling, J. (2003). Procurement of Sustainable Construction Services in the United States: the Contractor's Role in green Buildings. Available: http://www.uneptie.org/media/review/vol26no2-3/ voL26_no2-3.htm.

Rittel, H. W. J., and Webber, M. M. (1973). Dilemmas in a General Theory of Planning. Policy Sci 4 (2), 155-169. doi:10.2307/453152310.1007/bf01405730

Roberts, T. (2019). Insulating Homes with Sheep Wool. Available: https://www. buildwithrise.com/stories/can-you-use-sheep-wool-to-insulate-your-home\#: $\sim:$ text=According to the Healthy House,per inch\%2C while polyurethane and.

Robinson, D. T., Di Vittorio, A., Alexander, P., Arneth, A., Barton, C. M., Brown, D. G., et al. (2018). Modelling Feedbacks between Human and Natural Processes in the Land System. Earth Syst. Dynam. 9 (2), 895-914. doi:10.5194/esd-9-895-2018

Rovers, R. (2003). The Role of Policies in Promoting Sustainable Practices. Available: http://www.uneptie.org/media/review/vol26no2-3/voL26_no23.htm.

Sattler, M. A. (2003). Land Use and Sustainable Buildings: Design and Construction in Southern Brazil. Available: http://www.uneptie.org/media/ review/vol26no2-3/voL26_no2-3.htm.

Strand, S. M., and Sverre, F. (2003). Do standards and Regulations Supply the Necessary Incentive for Sustainable Building? Available: http://www.uneptie. org/media/review/vol26no2-3/voL26_no2-3.htm.

Tesla (2020). Solar Roof. Available: https://www.tesla.com/solarroof.

Timbercrete Pty. Ltd (2015). TIMBERCRETE ${ }^{\circledR}$ an Introduction. Timbercrete Pty. Ltd. Available: https://www.timbercrete.com.au/pdfs/Introduction_to_ Timbercrete.pdf.

Tsimplokoukou, K., Lamperti, M., and Negro, P. (2014). Building Design for Safety and Sustainability. Joint Res. Centre. doi:10.2788/338223

Uidhir, T. M., Rogan, F., Collins, M., Curtis, J., and Gallachóir, B. P. Ó. (2020). Improving Energy Savings from a Residential Retrofit Policy: A New Model to Inform Better Retrofit Decisions. Energy and Buildings 209, 109656. doi:10.1016/j.enbuild.2019.109656

Ulrich, W. (2012). Operational Research and Critical Systems Thinking-An Integrated Perspective. J. Oper. Res. Soc. 63, 1307-1322. doi:10.1057/ jors.2011.145

Ulrich, W., and Reynolds, M. (2010). Critical Systems Heuristics. in Systems Approaches to Managing Change: A Practical Guide. London: Springer, 243-292. doi:10.1007/978-1-84882-809-4_6

Ulrich, W. (1993). Some Difficulties of Ecological Thinking, Considered from a Critical Systems Perspective: A Plea for Critical Holism. Syst. Pract. 6, 583-611. doi:10.1007/BF01059480

UNEP (2003). Sustainable Building and Construction. Available: http://www. uneptie.org/media/review/vol26no2-3/voL26_no2-3.htm.

Vester, F. (1990). Ausfahrt Zukunft, Strategien Fur den Verkehr Von Morgen. in Eine System Untersuchug. 3rd ed. Munich: Wilhelm Heyne Verlag GmbH.

Vester, F. (2007). The Art of Interconnected Thinking. Munich: Springer book.

Vester, F. (2012). The Art of Interconnected Thinking: Ideas and Tools for a New Approach to Tackling Complexity. Germany: MCB-Verlag.

Vester, F. (2007). The Art of Interconnected Thinking: Tools and Concepts for a New Approach to Tackling Complexity. Munich, Germany: Springer book. 
Wang, N., and Adeli, H. (2014). SUSTAINABLE BUILDING DESIGN. J. Civ. Eng. Manag. 20 (1), 1-10. doi:10.3846/13923730.2013.871330

Walker, S., Khan, W., Katic, K., Maassen, W., and Zeiler, W. (2020). Accuracy of Different Machine Learning Algorithms and Added-Value of Predicting Aggregated-Level Energy Performance of Commercial Buildings. Energy and Buildings 209, 109705. doi:10.1016/j.enbuild.2019.109705

Wells, J. (2003). Social Aspects of Sustainable Construction: an ILO Perspective. Available: http://www.uneptie.org/media/review/vol26no2-3/voL26_no2-3.htm.

Wharton, A., and Payne, D. (2003). Promoting Innovation in Construction SMEs: an EU Case Study. Available: http://www.uneptie.org/media/review/vol26no23/voL26_no2-3.htm.

Windstorm, B., and Schmidt, A. (2013). A Report of Contemporary Rammed Earth Construction and Research in North America. Sustainability 5, 400-416. doi:10.3390/su5020400

Wuppertal (2021). UrbanUp" - Upscaling Strategies for an Urban Sharing Society," Upscaling Strategies For an Urban Sharing Society. Bengaluru: UrbanUp. Available: https://transzent.uni-wuppertal.de/de/forschung/upscalingstrategien-fuer-eine-urban-sharing-society-urbanup.html\#c11507.

Zabihi, H., Habib, D. F., and Mirsaeedie, L. (2012). Sustainability in Building and Construction: Revising Definitions and Concepts. Int. J. Emerg. Sci. 2 (4), 570-578.
Zhao, P., Li, X., Zhang, D., Xu, W., Liu, J., Wu, W., et al. (2021). A Simplified Method to Determine the Comprehensive Heat Transfer Quantity in Subway Tunnels. Energy and Buildings 247, 111090. doi:10.1016/j.enbuild.2021.111090

Conflict of Interest: The author declares that the research was conducted in the absence of any commercial or financial relationships that could be construed as a potential conflict of interest.

Publisher's Note: All claims expressed in this article are solely those of the authors and do not necessarily represent those of their affiliated organizations, or those of the publisher, the editors and the reviewers. Any product that may be evaluated in this article, or claim that may be made by its manufacturer, is not guaranteed or endorsed by the publisher.

Copyright $(2022$ Suberi. This is an open-access article distributed under the terms of the Creative Commons Attribution License (CC BY). The use, distribution or reproduction in other forums is permitted, provided the original author(s) and the copyright owner(s) are credited and that the original publication in this journal is cited, in accordance with accepted academic practice. No use, distribution or reproduction is permitted which does not comply with these terms. 